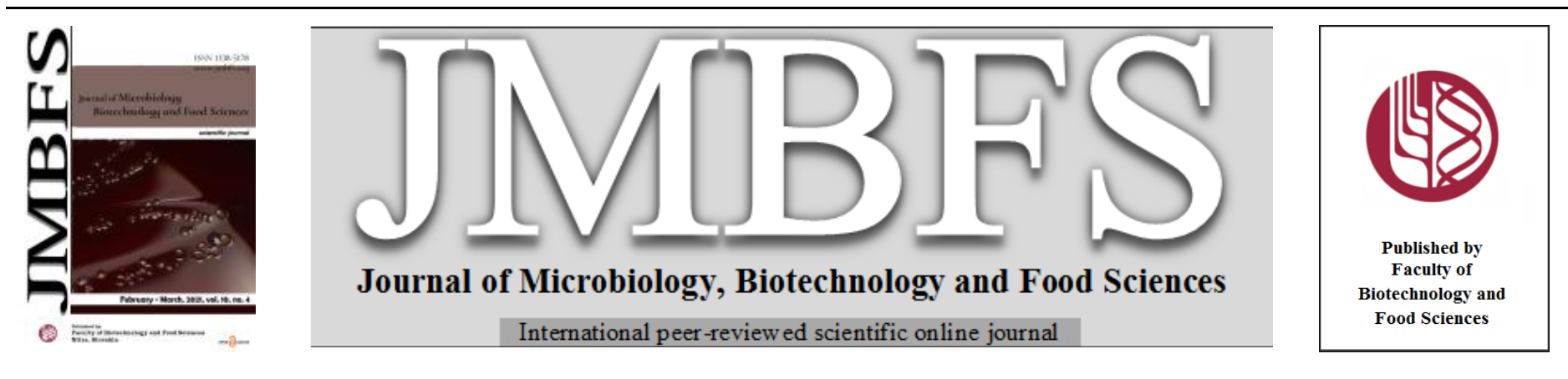

\title{
ACTINOBACTERIAL PIGMENT ASSISTED SYNTHESIS OF NANOPARTICLES AND ITS BIOLOGICAL ACTIVITY
}

\author{
Naresh Singh ${ }^{1}$, Bindu Naik', Vijay Kumar* ${ }^{1}$, Akhilesh Kumar ${ }^{1}$, Vivek Kumar ${ }^{1}$, Sanjay Gupta ${ }^{1}$ \\ Address(es): \\ ${ }^{1}$ Department of Biosciences, Swami Rama Himalayan University, Jollygrant, Dehradun, Uk, India-248016. \\ ${ }^{2}$ Department of Food Technology, UCALS, Uttaranchal University, Dehradun, UK-248007.
}

*Corresponding author: vijaygkp@gmail.com

doi: 10.15414/jmbfs.2021.10.4.604-608

\section{ARTICLE INFO}

Received 5. 11. 2019

Revised 10. 10. 2020

Accepted 15. 10. 2020

Published 1. 2. 2021

Regular article OPEN $\partial_{\text {ACCESS }}$

\begin{abstract}
Recently, the green synthesis of nanoparticles has gained considerable attention due to its benefits such as cost efficiency, simplicity, eco-friendly nature, biocompatibility and broad applications over conventional chemical and physical techniques. In this context twenty actinobacteria were isolated from the rhizospheric soil of wild carrot and screened for their pigment producing ability. These isolates belong to the genus Streptomyces (58\%), followed by Streptosporangium sp. (19\%), Nocardia sp. (11\%), Actinomadura sp. (8\%), and Micromonospora sp. (4\%). The most promising isolate (NS-05) producing the pink pigment has been taken for the synthesis of silver nanoparticles. The isolate NS-05 was identified as Streptomyces sp. based on cultural characteristics and 16S rDNA sequence analysis. It was most closely related with type strain Streptomyces fulvissimus DSM $40593^{\mathrm{T}}$, S. microflavus $\mathrm{NBRC} 13062^{\mathrm{T}}$, S. setonii NRRL ISP-5322 ${ }^{\mathrm{T}}$, S. anulatus RRL B- $2000^{\mathrm{T}}$ with a sequence similarity of $95.6 \%$ which shows that it may belong to novel species of Streptomyces. The bio-pigment assisted synthesized nanoparticles were characterized using UV-Vis, FTIR and Scanning electron microscopy studies. The average size of synthesized silver nanoparticles was $42.5 \mathrm{~nm}$ and has $\lambda$ max at $433 \mathrm{~nm}$. The synthesized nanoparticles showed promising activity against major pathogens like Staphylococcus aureus MTCC 2940, Bacillus subtilis MTCC 441 Salmonella typhi, Proteus vulgaris MTCC 6380, Escherichia coli MTCC 739. The findings of present research are promising, and this pigment can also be used for the green synthesis of other nanoparticles.
\end{abstract}

\section{INTRODUCTION}

Actinobacteria are Gram-positive, filamentous bacteria widely distributed in water, soil, and other natural ecosystems. The phylum Actinobacteria carries out a life cycle, which is complex and represents the main taxonomic parts between 18 major families now standard within the Domain Bacteria (Sharma et al., 2018). Most of the antibiotics of biological origin are of actinobacteria origin with Streptomyces being especially prolific. Based on several studies, antibiotics produced by the actinobacteria make $80 \%$ of the known antibiotics (Waksman, 1961). Likewise pigments such as red, violet, and orange produced by most of the genera of the actinobacteria. The red pigment synthesized by certain bacteria including actinobacteria, Serratia marsences and Streptomyces and this pigment belong to the family called prodigosin (Khanafari et al., 2006). In recent years, the demand for the natural product is increasing day by day and these natural products has become a site of interest and have been successful in attracting the population, while leaving the synthetic one. The synthetic colors are being replaced by natural colors (pigments). These pigments both natural and synthetic colors are widely used in various fields like food industries, paper industries, agricultural process, cosmetics, water science, researches, clothes and other technologies (Tuli et al., 2015).

In the development of nanoparticles with distinct shapes and sizes, the natural bio-moleculae have been reported to play an active role as the driving force for the design of greener, healthy and environmentally friendly nanoparticles' syrthesis protocols (Sharma et al., 2019). The synthesis of nanoparticles has got attention because it can be applied in various field. Similarly, the certain pigment-producing microorganisms can be a good source of natural pigment which can be used effectively. The pigments contains some functional group liable for the reduction of silver ions (Carvalho et al., 2011). The reduction is usually carried out by using pigments in aqueous/ ethanol or with microbial cells with a silver solution, usually silver nitrate. The presence of active chemicals in the extracted pigment and cells are responsible for the complex bio-reduction reaction process (Sadeghi et al., 2015; Baraka et al., 2017; John et al., 2020) Many researchers have synthesized nanoparticles based on chemical, physical and biological method (San Diego et al., 2020). In this context, we undertook the present study to isolate the pigment-producing actinobacteria and synthesis of pigment assisted nanoparticles and study its biological activity.

\section{MATERIAL AND METHODS}

\section{Isolation and characterization of actinobacteria}

The rhizosphere is in immediate contact with the plant roots and is actively enriched by the complex mixture of sources such as amino acids, sugar and other plant-based nutrients (Bais et al., 2006). This condition attracts a microbial community unique to plants (Essarioui et al ., 2017) hence, both plants and microorganisms are altered. Therefore, rhzospheric soil was used for isolation of actinobacteria. Ten grams of rhizosperic soil samples were collected from JollyGrant, Uttarakhand, India during February 2019. Three samples were collected from three different sites of Jollygrant. The soil samples were taken to the laboratory for its further analysis in sterilized polyethylene bags. The isolation and characterization of the actinobacteria was done by the according to a method described by Krishnamoorthy and Ekambaram, 2018; Kumar et al., 2012 ( a \&b). The neighbor-joining method was used to study the evolutionary history (Saitou and Nei, 1987). 1000 replicates selected for bootstrap analysis (Felsenstein, 1985). Kimura 2-parameter method was used for the study of evolutionary distances (Kimura, 1980). MEGA X software was used to perform phylogenetic analysis (Kumar et al., 2018).

\section{Culture media}

The culture media used during study were Actinomycetes isolation agr $(\mathrm{g} / \mathrm{L}$, Sodium caseinate-2.0, L-Asparagine-0.1, Sodium proponate-4.0, Dipotassium phosphate-0.5, Magnesium sulphate-0.1, ferrous sulphate-0.001, Agar-15.0) Nutrient agar media (g/L, Peptone-5.0, Yeast extract-5.0, HM peptone-1.0, Yeast extract-1.5, NaCl-5.0 , Agar-15.0, pH-7.2), Yest extract malt extract Agar (g/L, Peptone-5.0 ; yeast extract-3.0, malt extract-3.0, dextrose-10.0, agar- 20.0), Potato dextrose agar $(\mathrm{g} / \mathrm{L}$, Potatoes, infusion-200.0, dextrose -20.0, agar- 15.0) All the media were purchased from Himedia,Banglore, India. 


\section{Production of pigment from actinobacteria}

The isolates were grown on Actinomycetes isolation agar media (Himedia, India) and incubated at $27^{\circ} \mathrm{C}$ for 3 days until an extracellular water soluble pigment was produced. The produced pigment was extracted by crushing the agar with methanol and filtered through Whatman filter paper. The filtered solution concentrated by using Rota vacuum and converted into powder.

\section{Nanoparticle synthesis}

$\mathrm{AgNO}_{3}$ was the silver precursor and the solution was prepared using sterilized distilled water and kept in dark to avoid photo-reduction. All the glasswares were cleaned using aqua-regia $\left(\mathrm{HNO}_{3}: \mathrm{HCl}, 3: 1(\mathrm{v} / \mathrm{v})\right.$ and washed thoroughly using distilled water (Karthika et al., 2015). The solid pigment was dissolved in sterile double distilled water, out of which $600 \mu \mathrm{l}$ transferred to a test tube containing $400 \mu \mathrm{l}$ of $1 \mathrm{mM}$ solution of silver nitrate. The reaction mixture was incubated at room temperature for 16 to $24 \mathrm{hrs}$ in the dark. After incubation, the change in color was observed from red to brown.

\section{Characterization of synthesized nanoparticles}

After 16-24 hrs of incubation, the reaction mixture centrifuged at $15000 \mathrm{rpm}$ for 30 min. (REMI, India). The supernatant was discarded and the black-colored precipitate was re-dissolved in double-distilled water and scanned for $\lambda$ max from 200-1100 nm using UV-Vis spectrophotometer (UV-1800 Shimadzu, Japan). The potential biomolecules present in the pigment of actinobacteria responsible for reducing and capping the bio-reduced silver nanoparticles was studied by using Fourier Transform Infrared (FTIR) Spectroscopy Measurements (Raut et al., 2009). To analyze the shape and size of nanoparticles, SEM analysis was performed. The sample was sonicated for $14 \mathrm{~min}$. then loaded on the carbon tape. The solvent was allowed to evaporate and then the sample was coated with gold and analyzed using SEM (Duran et al., 2005).

\section{Antibacterial assay}

Antibacterial assay was carried out using agar well diffusion method according to the method described by Kumar et al., 2012 (a \&b). Antimicrobial activity was detected by measuring the zone of inhibition in $\mathrm{mm}$ (including the wells diameter) appeared after $24 \mathrm{hrs}$ at $37^{\circ} \mathrm{C}$. Pigment and $\mathrm{AgNO}_{3}$ was used as control. The tested bacteria were Staphylococcus aureus MTCC 2940, Bacillus subtilis MTCC 441 Salmonella typhi, Proteus vulgaris MTCC 6380, and Escherichia coli MTCC 739.

\section{RESULTS AND DISCUSSION}

\section{Isolation and characterization of isolates}

The occurrence and distribution of actinobacteria in different soil samples are given in table 1 . Based on colony morphology, 25 isolates were selected. These isolates were tentatively isolates up to genus level as described by Kumar et al. (2012). During the study, it was recorded that Streptomyces sp. was dominant $(58 \%)$ followed by Streptosporangium $\mathrm{sp}(19 \%)$, Nocardia $\mathrm{sp}$ (11\%), Actinomadura sp. (8\%) and Micromonospora sp. (4\%) as shown from Fig.1

Table 1 Occurrence and distribution of actinobacteria in rhizospheric soil

\begin{tabular}{lll} 
Sample & C.F.U & Morphotypes \\
\hline S-1 & $15.0 \times 10^{5}$ & 5 \\
S-2 & $30.0 \times 10^{5}$ & 10 \\
S-3 & $25.0 \times 10^{5}$ & 10 \\
& Total & $\mathbf{2 5}$ \\
\hline
\end{tabular}

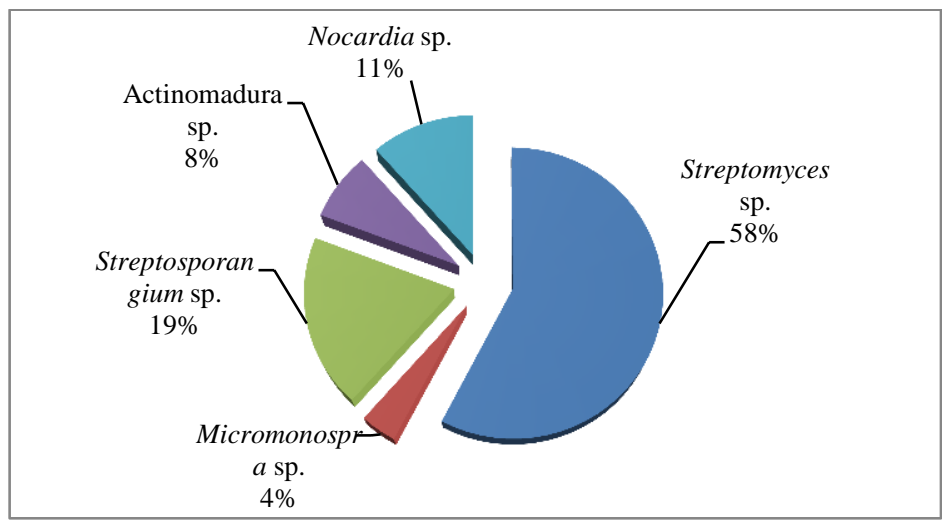

Figure 1 Distribution of actinobacteria in rhizospheric soil

These isolate were screened for their pigment producing ability and only one isolate (NS-05) was able to produce pink colored pigment and was further identified by using polyphasic approach. Isolate NS-05 produced entensively branched substrate and aerial hyphae. It bears light pink colored flexous spore chain on the aerial mycelium (Fig. 2). . The cultural characteristics of the actinobacterial isolate NS-05 are given in table 2. Good growth was recored in all the media tested. However, pigment was only produed in AIA and NAM. The physiochemical characteristic of NS-05 with most closely related type stains has been given in table 3. Based on the 16S rDNA sequence (1016 Nucleotides) analysis the tested isolate waas identified as Streptomyces species and the sequence was submitted to GenBank under the accession number MN173858. Based on pairwise sequence analysis the isolated was most closely related to Streptomyces fulvissimus DSM 40593T, S. microflavus NBRC13062T, S. setonii NRRL ISP-5322T and S. anulatus NRRL B-2000T with a sequence similarity of $95.6 \%$. According to Stackebrandt and Goebel (1994) the organisms having a sequence similarity of $97 \%$ or less may belong to novel species. Hence, this isolate may be the novel species of Streptomyces. Moreover, isolate NS-05 is out-group with all the most closely related species which further confirms its novelty (Fig. 3). The isolate NS-05 can also be distinguished from type strains in many other chacteristics. The isolate NS-05 produced flexous spore chains while most closly related species produced spirals and rectiflexibiles. The spore mass color was light pink in case of NS-05 whereas it was red, gray and yellow towhile for Streptomyces fulvissimus DSM 40593T, $S$ microflavus NBRC13062T, and S. setonii NRRL ISP-5322T respectively. NS-05 showed negative test for lipase actvity whereas type strains showed postive results.Comparatively no growth was recorded at $0.001(\mathrm{w} / \mathrm{v})$ Potassium terullite and in cysteine. Therefore, NS-05 may represent a novel species of Streptomyces.

Table 2 The cultural characteristics of the actinobacterial isolate NS-05

\begin{tabular}{lcccc}
\hline Media & $\begin{array}{c}\text { Aerial } \\
\text { Mycelium }\end{array}$ & $\begin{array}{c}\text { Substrate } \\
\text { mycelium }\end{array}$ & Spores & Pigment \\
\hline AIA & Dull white & Dark Brown & ++ & Dark Pink \\
NAM & Light cream & Dark brown & ++ & Light Pink \\
YEMEA & White & Yellow & ++ & - \\
PDA & White & Brown & ++ & - \\
\hline
\end{tabular}

AIA- Actinomycetes isolation agar, NAM-Nutrient agar media, YEMEA-Yeast extract malt extract agar,PDA-Potato dextrose agar

Table 3 Differentiation of Streptomyces sp. NS-5 with most closely related type strains (Locci, 1989)

\begin{tabular}{|c|c|c|c|c|}
\hline Characteristics & Isolate NS-05 & $\begin{array}{l}\text { Streptomyces fulvissimus } \\
\text { DSM 40593T }\end{array}$ & $\begin{array}{ll}S . & \text { microflavus } \\
\text { NBRC13062T, }\end{array}$ & $\begin{array}{l}\text { S. setonii NRRL ISP- } \\
5322 \mathrm{~T}\end{array}$ \\
\hline Spore chain & Flexous & Rectiflexibiles & Spirals & Rectiflexibiles \\
\hline Spore mass & Light pink & Red & Gray & Yellow to white \\
\hline Mycelial pigment & Brown & Red orange & Yellow-brown & Yellow brown \\
\hline Diffusible pigment & Pink & - & - & Yellow brown \\
\hline $\begin{array}{l}\text { Lipase activity } \\
\text { Growth at }\end{array}$ & - & +++ & + & +++ \\
\hline $7 \%(\mathrm{w} / \mathrm{v}) \mathrm{NaCl}$ & +++ & + & - & ++ \\
\hline $\begin{array}{l}0.01 \% \quad(w / v) \text { Sodium } \\
\text { azide }\end{array}$ & +++ & - & ++ & + \\
\hline $0.1 \%(\mathrm{w} / \mathrm{v})$ Phenol & + & ++ & +++ & +++ \\
\hline $\begin{array}{l}0.001(\mathrm{w} / \mathrm{v}) \text { Potassium } \\
\text { terullite } \\
\text { Nitrogen source }\end{array}$ & - & +++ & ++ & ++ \\
\hline L-cysteine & - & ++ & ++ & ++ \\
\hline
\end{tabular}




\begin{tabular}{|c|c|c|c|c|}
\hline L- valine & + & +++ & + & + \\
\hline L-phenylalanine & ++ & +++ & +++ & ++ \\
\hline L-histidine & ++ & +++ & + & ++ \\
\hline \multicolumn{5}{|l|}{ Carbon source } \\
\hline Sucrose & +++ & + & +++ & + \\
\hline Mannitol & ++ & +++ & +++ & +++ \\
\hline Raffinose & + & ++ & +++ & + \\
\hline Melibiose & + & ++ & + & + \\
\hline Dextran & - & + & - & +++ \\
\hline Inositol & +++ & +++ & + & + \\
\hline
\end{tabular}

Symbols used: +++ good; ++ Fair; + poor ; - negative

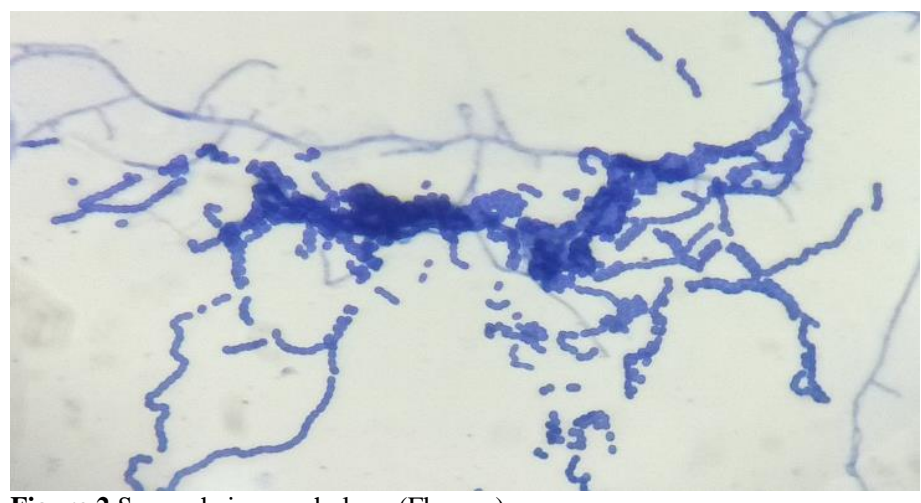

Figure 2 Spore chain morphology (Flexous)

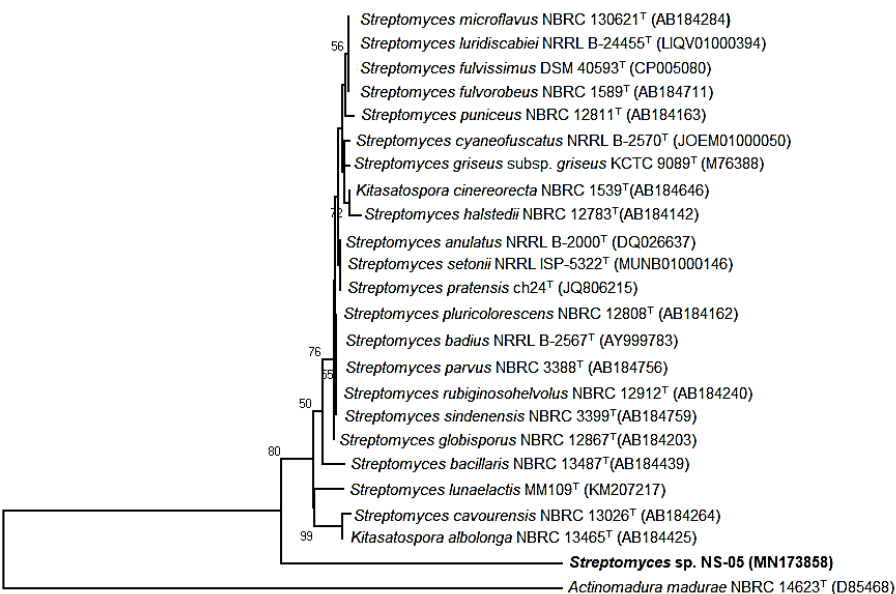

\subsection{2}

Figure 3 Neighbour-joining phylogenetic tree based on 16S rDNA gene sequences, showing the relationships between tested strain Streptomyces sp. NS06 and the most closely related with type strains of Streptomyces. Only values above $50 \%$ are given.

\section{Characterization of the synthesized nanoparticles}

In modern technology, synthesis of nanoparticles is one of the lime-lighted topic, especially biosynthesis of nanoparticles from the pigment produced naturally by microorganisms under exploitation. Hence, in the present study was focused on the synthesis of silver nanoparticles using the pigment produced from Streptomyces sp. NS-05. The silver nanoparticles' formation was indicated by observing the change in color from pink to brown after addition of silver nitrate (Shah et al., 2015) as shown in Fig.4.

Table $4 \lambda$ max (peak detection) for the synthesized nanoparticles

\begin{tabular}{lllll} 
S. No. & \multicolumn{2}{l}{ Control (Pigment) } & \multicolumn{2}{c}{ T1 (Pigment $+\mathbf{A g N O}_{3}$ ) } \\
\hline 1 & $\lambda \max (\mathrm{nm})$ & $\mathrm{Abs}$ & $\lambda)(\mathrm{nm})$ & $\mathrm{Abs}$ \\
2 & 540.00 & 0.137 & 735.00 & 0.018 \\
3 & 508.00 & 0.064 & 433.00 & 1.213 \\
\hline
\end{tabular}

After 16 hrs of incubation reaction mixture was scanned ( between 200-1100nm) using UV-Vis spectroscopy as a result of which the bio-reduction of silver ion was monitored. The $\lambda$ max was recorded at $430 \mathrm{~nm}$ (Fig.5 and table 4 ), which indicates that the nanoparticles were synthesized. The dark brown color was exhibited by the silver nanoparticles (Mulvaney, 1996; Gao et al., 2014). SEM analysis of the silver nanoparticles reveals that they are predominantly spherical
(Fig. 6). The average size of the synthesized nanoparticles was $42.5 \mathrm{~nm}$. The action of nanoparticles on disease causing organism is related to the shape size and concentration with the synthesized nanoparticles. The smaller the nanoparticle the more is its activity against pathogen (Chauhan et al. 2013). Possible bio-molecules responsible for $\mathrm{Ag}^{+}$ions reduction and capping were identified using FTIR analysis. The major spectra (Fig.7) of nanoparticles obtained spectrum resulted in peak value at $3454.83 \mathrm{~cm}^{-1}$ corresponding to $\mathrm{OH}$ stretching in alcohol and phenolic compound and peak at 1636 corresponds to amide group due to carbonyl stretch in proteins, and the peak identified at 655.84 $\mathrm{cm}^{-1}$ as halogen compounds. Researchers have proved that presence of thiols, amino acids and alcohols protect particles from sedimentation, agglomeration, or losing their surface properties (Oliveira et al., 2005; Iravani et al., 2014).

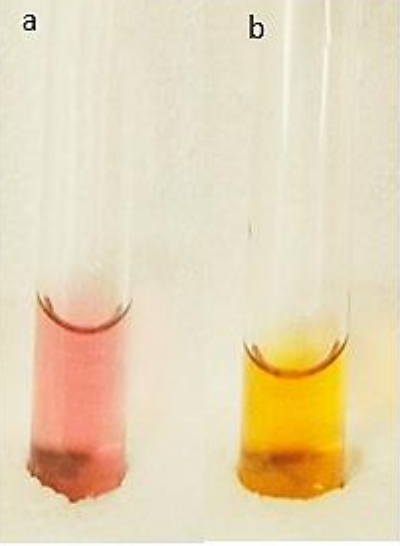

Figure 4 The colour of the extracted pigment (a) before addition of silver nitrate (b) after addition of silver nitrate
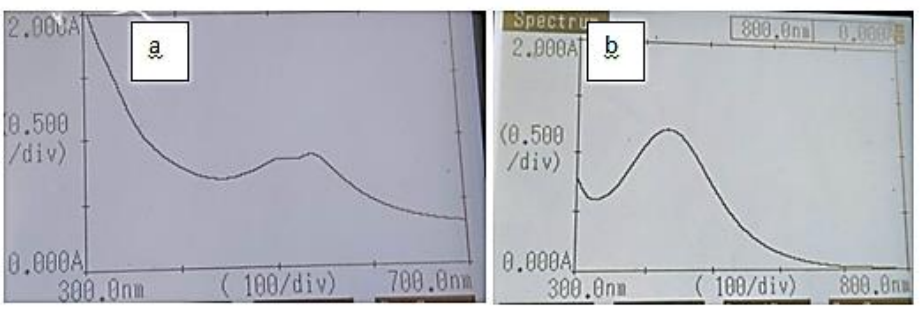

Figure 5 UV-Vis spectroscopy, a, Control-Pigment ( $\lambda$ max, 504 and 580nm); bSynthesized nanoparticle: peak at $433 \mathrm{~nm}$

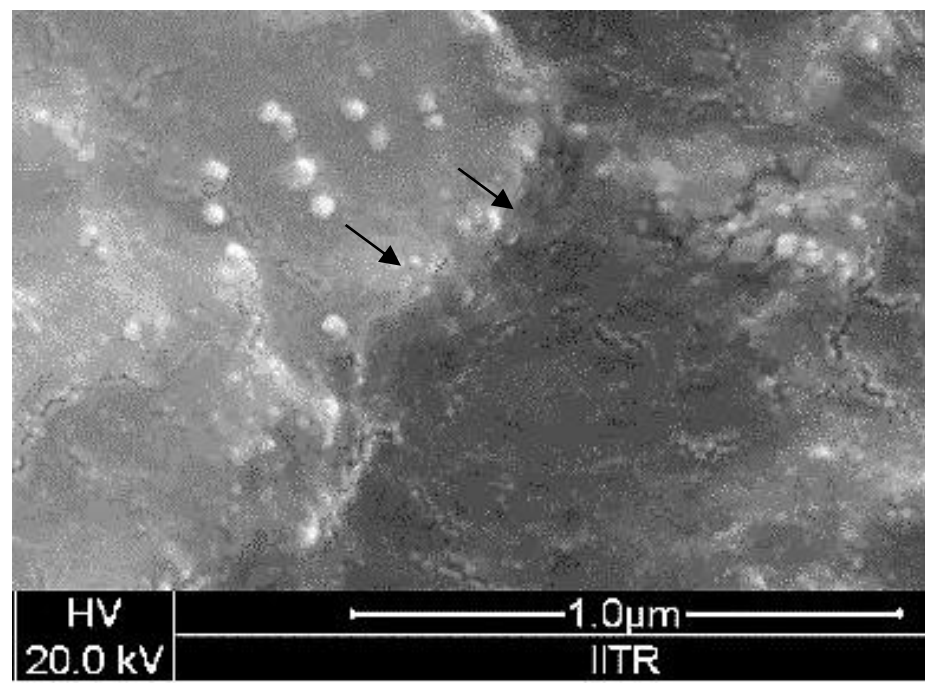

Figure 6 SEM analysis of silver nanoparticles synthesized from pigment produced by Streptomyces sp. The black arrows indicates the nanoparticles. 


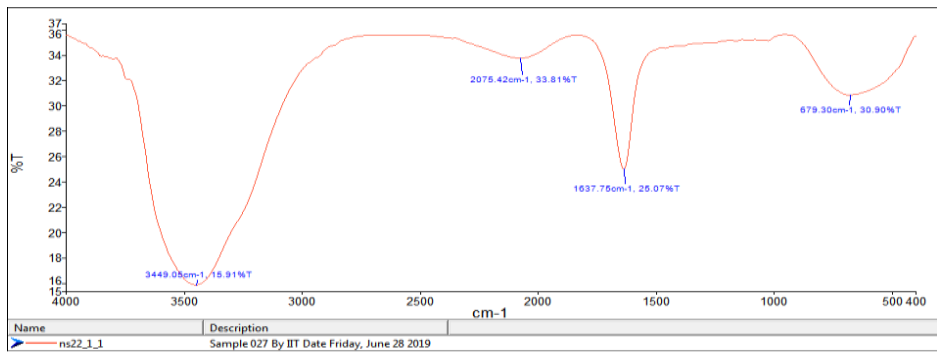

Figure 7 FTIR analysis of silver nanoparticles synthesized from pigment produced by Streptomyces sp.

\section{Antimicrobial activity of silver nanoparticles synthesized}

The antimicrobial activities of the synthesized nanoparticle are given in table 5. It showed maximum zone of inhibition against $B$. subtilis MTCC $441(19.00 \pm$ $1.00 \mathrm{~mm}$ ) followed by $S$. aureus MTCC $2940(18.00 \pm 1.00 \mathrm{~mm})$, S. pyogenes $(17.00 \pm 0.47 \mathrm{~mm}), P$. vulgaris MTCC $6380(16.00 \pm 1.00 \mathrm{~mm})$ and E. col MTCC $739(14.00 \pm 1.00 \mathrm{~mm})$. The pigment alone showed activity against E. coli and $P$. vulgaris only, while the activity was enhanced when silver nanoparticles was synthesized. It is usually recognized that the antimicrobial activity of synthesized nanoparticles are due to electrostatic interaction between cell wall of bacteria (negative charged) and nanoparticles (Positive charge). This electrostatic interaction finally leads to the death of the microbial cells Hajipour et al., 2012; Wnag et al., 2017). The enhancement of antimicrobial activity may be due to the free conjugation form of silver nanoparticles (AgNPs) as revealed by FTIR data (El-Baz et al., 2016).

Table 5 Antimicrobial activity of silver nanoparticles synthesized by well diffusion method

\begin{tabular}{lccc}
\hline Test organism & \multicolumn{3}{c}{ Inhibition zone diameter in mm } \\
\hline & Synthesized nanoparticles & Pigment (Control ) & AgNo $_{3}$ (Control ) \\
\hline S. aureus MTCC 2940 & $18.00 \pm 1.00$ & - & $9.00 \pm 1.00$ \\
E. coli MTCC 739 & $14.00 \pm 1.00$ & $5.00 \pm 1.00$ & $8.00 \pm 1.00$ \\
P. vulgaris MTCC 6380 & $16.00 \pm 1.00$ & $8.00 \pm 1.00$ & $5.00 \pm 1.00$ \\
S. typhi & $10.00 \pm 0.47$ & - & $9.00 \pm 1.00$ \\
Bacillus subtilisMTCC 441 & $19.00 \pm 1.00$ & - & $10.00 \pm 0.3$ \\
Streptococcus pyogens & $17.00 \pm 0.47$ & - & $10.00 \pm 0.40$ \\
\hline
\end{tabular}

Average of triplicates \pm Standard deviation; -, No zone of inhibition

\section{CONCLUSION}

The rhizosperic soil is rich source of Actinobacteria mainly the genera Streptomyces, Streptosporangium sp, Nocardia sp, Actinomadura sp, and Micromonospora $\mathrm{sp}$. The most promising isolate (NS-05) producing the pink pigment was most closely related with the type strain Streptomyces fulvissimus DSM 40593T, S. microflavus NBRC13062T, S. setonii NRRL ISP-5322T, $S$ anulatus NRRL B-2000T with a sequence similarity of $95.6 \%$ which indicates, that it may belong to novel species of Streptomyces. Average size of synthesized AgNPs were found to $42.5 \mathrm{~nm}$ and have $\lambda$ max at $433 \mathrm{~nm}$. Synthesized nanoparticles showed promising activity against both Gram-positive and Gramnegative bacterial pathogens. The findings of present research are promising, and this pigment can also be used for the green synthesis of other nanoparticles.

Acknowledgements: Authors are thankful to Management Swami Rama Himalayan University, Dehradun, UK, India for providing the lab facilities to carry out this research. We are also thankful to Indian Institute of Technology (IIT), Roorkee, India for providing FTIR and SEM facilities.

\section{Conflict of interest: None}

\section{REFERENCES}

Sharma P, Singh TA, Bharat B, Bhasin S, Modi HA. Approach towards differen fermentative techniques for the production of bioactive actinobacterial melanin. Beni-Suef. Univ. J Basic Appl Sci. 2018; 7(4):695-700 https://doi.org/10.1016/j.bjbas.2018.08.002

Waksman SA. The role of antibiotics in nature. Perspectives in biology and medicine. 1961; 4(3): 271-87. https://doi.org/10.1353/pbm.1961.0001

Khanafari A, Assad MM, Fakhr FA. Review of Prodigiosin, Pigmentation in Serratia marcescens. Online J Biol Sci. 2006; 6 (1): 1-13. https://doi.org/ 10.3844/ojbsci.2006.1.13

Tuli HS, Chaudhary P, Beniwal V, Sharma AK. Microbial pigments as natura color sources: current trends and future perspectives. J Food Sci Technol. 2015 52(8): 4669-4678. https://doi.10.1007/s13197-014-1601-6

Sharma D, Kanchi S, Bisetty K (2019). Biogenic synthesis of nanoparticles: A review. Arabian Journal of Chemistry, 2019; 12 (8), 3576-3600. https://doi.org/10.1016/j.arabjc.2015.11.002

Carvalho RF, Takaki M, Azevedo RA. Plant pigments: the many faces of light perception. Acta Physiol Plant. 2011; 33(2), 241-248. https://doi.10.1007/s11738-010-0533-7

Sadeghi B, Mohammadzadeh M, Babakhani B. Green synthesis of gold nanoparticles using Stevia rebaudiana leaf extracts: characterization and their stability. J Photochem. Photobiol. B. 2015; 148: 101-106 https://doi.org/10.1016/j.jphotobiol.2015.03.025.

Baraka A, Dickson S, Gobara M, El-Sayyad GS, Zorainy M, Awaad MI, Hatem H, Kotab MM, Tawfic AF. Synthesis of silver nanoparticles using natura pigments extracted from Alfalfa leaves and its use for antimicrobial activity. Chemical Papers 2017; $21(11), \quad 271-2281$ https://doi.org/10.1007/s11696-017-0221-9
John MS, Nagoth JA, Ramasamy KP, Mancini A, Giuli G, Natalello A, Ballarini P, Miceli C, Pucciarelli, S. Synthesis of Bioactive Silver Nanoparticles by a Pseudomonas Strain Associated with the Antarctic Psychrophilic Protozoon Euplotes focardii. Marine Drugs, 2020; 18(1), 38. doi:10.3390/md18010038

San Diego KD, Alindayu JIA, Baculi RQ. Biosynthesis of gold nanoparticles by bacteria from hyperalkaline spring and evaluation of their inhibitory activity against pyocyanin production. Journal of Microbiology, Biotechnology and Food Sciences, 2020; 9(4), 781-787. doi: 10.15414/jmbfs.2018.8.2.781-787

Bais HP, Weir TL, Perry LG, Gilroy S, Vivanco JM. The role of root exudates in rhizosphere interactions with plants and other organisms. Annu Rev Plant Biol 2006;57, 233-266. doi:10.1146/annurev.arplant.57.032905.105159

Essarioui A, LeBlanc N, Kistler HC, Kinkel L L. Plant community richness mediates inhibitory interactions and resource competition between Streptomyces and Fusarium populations in the rhizosphere. Microb. Ecol. 2017; 74, 157-167. https://doi.10.1007/s00248-016-0907-5

Adelere I and Lateef A. A novel approach to the green synthesis of metallic nanoparticles: the use of agro-wastes, enzymes, and pigments. Nanotechnology Reviews, 2016; 5(6): 567-587. https://doi.org/10.1515/ntrev-2016-0024.

Krishnamoorthy S., Ekambaram N. Biogenic synthesis of silver nanoparticles using pigment producing Streptomyces sp and Its drug binding assay. Int J Sci Res Biol Sci 2018; 5(5): 102-107. https://doi.org/10.26438/ijsrbs/v5i5.102107. Kumar, V., Bharti, A., Negi, Y.K., Gusain, O., Pandey, P., Bisht, G.S., 2012a Screening of actinomycetes from earthworm castings for their antimicrobial activity and industrial enzymes. Braz J Microbiol. 43(1), 205-214 https://doi.10.1590/S1517-838220120001000022

Kumar, V., Bharti, A., Gupta, V.K., Gusain, O. and Bisht, G.S., 2012b. Actinomycetes from solitary wasp mud nest and swallow bird mud nest: isolation and screening for their antibacterial activity. World $\mathbf{J}$ Microbiol Biotechnol. 28(3), 871-880. https://doi. 10.1007/s11274-011-0884-2.

Saitou N, and Nei M. The neighbor-joining method: a new method for reconstructing phylogenetic trees. Mol Biol Evol. 1987; 4(4): 406-425. https://doi.10.1093/oxfordjournals.molbev.a040454

Felsenstein J. Confidence limits on phylogenies: An approach using the bootstrap. Evolution. 1985; 39:783-791. https://doi.10.1111/j.1558 5646.1985.tb00420.x

Kimura, M., 1980. A simple method for estimating evolutionary rate of base substitutions through comparative studies of nucleotide sequences. J Mo Evol. 16: 111-120. https://doi.10.1007/bf01731581.

Kumar, S., Stecher , G., Li, M., Knyaz, C., Tamura, K., 2018. MEGA X Molecular Evolutionary Genetics Analysis across computing platforms. Mol Biol Evol 35: 1547-1549. https://doi.10.1093/molbev/msy096.

Karthika D, Vadakkan K, Ashwini R, Shyamala A, Hemapriya J, Vijayanand S Prodigiosin Mediated Biosynthesis of Silver Nanoparticles (AgNPs) and Evaluation of its Antibacterial Efficacy. Int J Current Microbiol Appl Sci. 2015 4 (11): 868-874

Rajesh W, Lakkakula JR, Kolekar NS, Mendhulkar VD, Kashid SB, 2009. Phytosynthesis of Silver Nanoparticle Using Gliricidia sepium (Jacq.); Cur Nanosci. 2009; 5: 117-122. https://doi.10.2174/157341309787314674

Durán N, Marcato PD, Alves OL, De Souza GI, Esposito E. Mechanistic aspects of biosynthesis of silver nanoparticles by several Fusarium oxysporum strains. J Nanobiotechnol. 3(1): 8. https://doi.10.1186/1477-3155-3-8 
Stackebrandt E, Goebel BM 1994. Taxonomic note: a place for DNA-DNA reassociation and $16 \mathrm{~S}$ rRNA sequence analysis in the present species definition in bacteriology. Int J Syst Evol Microbiol.1994; 44(4): 846-849. https://doi.org/10.1099/00207713-44-4-846

Shah M, Fawcett D, Sharma S, Tripathy S, Poinern G. Green synthesis of metallic nanoparticles via biological entities. Material . 2015; 8(11), 7278-308 https://doi. 10.3390/ma8115377.

Mulvaney P. Surface plasmon spectroscopy of nano sized metal particles. Langmuir. 196; 1: 788-800. https://doi.org/10.1021/la9502711

Gao Y, Huang Q, Su Q, Liu R. Green synthesis of silver nanoparticles at room temperature using Kiwifruit juice. Spectrosc Lett. 2014; 47(10):790-795 https://doi.10.1080/00387010.2013.848898

Chauhan, R, Kumar A, Abraham J, 2013. Biological approach to the synthesis of silver nanoparticles with Streptomyces sp JAR1 and its antimicrobial activity. Sci Pharm. 2013; 81 (2): 607-621. https://doi.org/10.3797/scipharm.1302-02.

Oliveira M, Ugarte D, Zanchet D, Zarbin. Influence of synthetic parameters on the size, structure, and stability of dodecanethiol-stabilized silver nanoparticles. J
Colloid
Interface
Sci.
2005
292:
429-435.

https://doi.org/10.1016/j.jcis.2005.05.068

Iravani S, Korbekandi H, Mirmohammadi SV, Zolfaghari B. Synthesis of silver nanoparticles: chemical, physical and biological methods. Res Pharma Sci. 2014;9(6):385-406

Hajipour MJ, Fromm K M, Ashkarran A A, de Aberasturi DJ. , de Larramendi I $\mathrm{R}$, Rojo $\mathrm{T}$ et al. Antibacterial properties of nanoparticles. Trends Biotechnol. 2012; 30(10): 499-511. https://doi.org/10.1016/j.tibtech.2012.06.004

Wang L, Hu C, and Shao L. (2017). The antimicrobial activity of nanoparticles: present situation and prospects for the future. Int J. Nanomedicine, 2017; 12: 1227-1249. https://doi.10.2147/IJN.S121956

El-Baz, A.F., El-Batal, A.I, Abomosalam, F.M., Tayel, A.A., Shetaia, Y.M., Yang, S.T., 2016. Extracellular biosynthesis of anti-Candida silver nanoparticles using Monascus purpureus. J Basic Microbiol. 2016; 56(5): 531-540. https://doi.10.1002/jobm.201500503 